\title{
Comparative evaluation of the subtractive and additive manufacturing on the color stability of fixed provisional prosthesis materials
}

\author{
Young-Ji Lee, Sang-Chun Oh* \\ Department of Prosthodontics, College of Dentistry, Wonkwang University, Iksan, Republic of Korea
}

\begin{abstract}
Purpose: The purpose of this study is to compare the color stability of provisional restorative materials fabricated by subtractive and additive manufacturing. Materials and Methods: PMMA specimens by subtractive manufacturing and conventional method and bis-acryl specimens by additive manufacturing were fabricated each 20. After immersing specimens in the coffee solution and the wine solution, the color was measured as CIE Lab with a colorimeter weekly for 4 weeks. Color change was calculated and data were analyzed with one-way ANOVA and the Tukey multiple comparisons test $(\alpha=0.05)$. Results: PMMA provisional prosthetic materials by subtractive manufacturing showed superior color stability compared to bis-acryl provisional prosthetic materials by additive manufacturing $(P<0.05)$, and showed similar color stability to the PMMA provisional prosthetic materials by conventional method $(P$ $>0.05$ ). Conclusion: It is recommended to fabricate provisional restorations by subtractive manufacturing in areas where esthetics is important, such as anterior teeth, and consideration of the color stability will be required when making provisional prosthetic using additive manufacturing. (J Dent Rehabil Appl Sci 2021;37(2):73-80)
\end{abstract}

Key words: color stability; computer-aided design/computer-aided manufacturing (CAD-CAM); additive manufacturing; subtractive manufacturing

\section{서론}

임시 보철물은 최종 보철물 수복 전까지 지대치를 보 호하고, 치아의 정출이나 경사를 방지하고, 저작을 도우 며, 심미성을 제공하는 역할을 한다. ${ }^{1}$ 임시 보철물의 심미 성은 전치부와 같이 심미적으로 중요한 부위에서 환자의 만족감을 위해 중요한데, 특히 형태와 색상은 심미를 결 정짓는 주 요소이다. ${ }^{2}$ 또한 임시 보철물의 변색은 환자의 불만족으로 연결되므로, ${ }^{3}$ 임시 보철물의 색을 유지하는 것이 중요하며, ${ }^{4}$ 심미영역에서 임시 수복의 성공여부는 색 안정성과 변색 저항성이라고 할 수 있다.

임시치아를 제작하는 기존의 방법은 환자의 구강내 삭 제된 치아에서 제작되는 직접법과 구강 외 모형 상에서

*Correspondence to: Sang-Chun Oh

Professor, Department of Prosthodontics, College of Dentistry, Wonkwang University, 77 Doonsan-ro, Seo-gu, Daejeon, 35233, Republic of Korea Tel: +82-42-366-1102, Fax: +82-42-366-1115, E-mail: scoh@wku.ac.kr Received: January 20, 2021/Last Revision: February 21, 2021/Accepted: March 12,2021
제작하는 간접법이 있다. 최근에는 정확하고 효율적인 computer aided design and computer aided manufacturing (CAD-CAM) 시스템 활용이 확대되면서 밀링기를 이용해 절삭하는 절삭가공과 $3 \mathrm{D}$ 프린터를 이용하는 적 층가공이 사용되기 시작하여 제작과정이 간단해지고 정 확해졌다. 또한 디지털 파일로 저장된 디자인 자료로 인 해 기공사와 치과의사간의 소통이 용이해졌다. ${ }^{5}$

절삭가공으로 임시 보철물 제작 시 $\mathrm{CAD}$ 를 이용하여 디자인한 후 미리 중합된 블록 형태의 PMMA를 절삭하 여 짧은 시간내에 우수한 물리적 성질을 갖고 정확한 임 시 보철물의 제작이 가능하다. ${ }^{6}$ 그러나 절삭 방식의 특성 상 재료와 절삭기구의 소모가 크다는 문제점을 가지고 있다. 
적층가공으로 임시 보철물 제작 시 사용하는 $3 \mathrm{D}$ 프린 터는 주로 Stereolithography apparatus (SLA) 또는 Digital light processing (DLP)방식이며, 적층 속도가 빨라 제 작시간을 줄일 수 있고, 불필요한 작업 공정을 생략할 수 있어 비용 절감도 가능하다. 또한, 세밀한 표면조도와 정 밀도 있는 제작이 가능하다.

절삭가공과 적층가공의 사용이 점차 증가하고 있으나 임시 보철 재료의 색 안정성에 대한 연구는 최근에 진행 되기 시작하여 아직 부족한 상태이다. Almohareb 등은 절삭가공한 CAD-CAM블록이 전통적인 PMMA나 bisacryl에 비해 뛰어난 색 안정성을 갖는다는 결과를 얻었 고, ${ }^{7}$ Elagra는 전통적인 PMMA와 절삭가공한 PMMA 블록은 뛰어난 색 안정성을 보였으며 두 재료의 임상적 으로 유의한 차이는 발견되지 않았다고 보고하고 있다. ${ }^{8}$ Shin 등의 연구에 의하면 3D 프린팅된 임시 보철 재료는 $\mathrm{CAD} / \mathrm{CAM}$ 블록보다 낮은 색 안정성을 보였으며, 침전 기간이 길수록 큰 색 변화를 보였다. ${ }^{9}$ Gruber 등의 연구 에서도 열중합 레진과 절삭가공한 PMMA 레진에 비해 적층가공한 레진에서 낮은 색 안정을 보였다는 결과를 얻었다. ${ }^{10}$ 또한 Revilla-León 등은 적층가공으로 제작한 임시 보철 재료 간 상당한 색의 차이가 있고 이는 임상에 서 허용 불가능한 색의 불일치로 연결될 수 있다고 보고 하였다. ${ }^{11}$

선행 연구는 대부분 전통적인 방식의 PMMA와 절삭 가공으로 제작한 PMMA를 비교하는 연구에 집중되어 있으며, 적층가공을 이용해 제작된 임시 보철 재료에 대 한 연구는 적었다. 이에 본 연구에서는 CAD-CAM 방식 중 절삭가공과 적층가공으로 제작한 임시 보철 재료의 색 안정성을 비교 평가하고자 하였다.

\section{연구 재료 및 방법}

자가중합형 PMMA (Tokuso CureFast, Tokuyama Dental, Tokyo, Japan)를 이용해 전통적인 방법으로 제작 한 시편을 CON군, 밀링기(ARUM 5X-200, DOOWON ID, Daejeon, Korea)로 PMMA블록(PMMA DISK, YAMAHACHI DENTAL, Gamagori, Japan)을 절삭 가공한 시편을 MIL군, 그리고 DLP 타입의 3D 프린터 (DIO PROBO, DIO, Busan, Korea)를 이용하여 적층가 공한 광경화성 수지(3D polymer, Myeong Moon dental, Daegu, Korea)를 DLP군이라 명명하였고(Table 1), MIL 군과 DLP군의 색 안정성을 비교하기 위해 $\mathrm{CON}$ 군을 대 조군으로 설정하였다.

$\mathrm{CON}$ 군의 시편 제작을 위해 가로와 세로가 $100 \mathrm{~mm}$ 인 정사각형 금속판에 직경 $10 \mathrm{~mm}$, 두께 $2 \mathrm{~mm}$ 의 음각이 있는 금속 주형을 제작하였다(Fig. 1). 광학 유리판 위에 주형을 위치시킨 후 제조사의 지시에 따라 액과 분말을 혼합하여 주형내부에 채워 넣었다. 그 상방에 광학 유리 판을 위치시킨 후 경화될 때까지 가압해주며 기포가 최 소한으로 발생하도록 하였다. MIL군의 시편 제작을 위 해 CAD software로 직경 $10 \mathrm{~mm}$, 두께 $2 \mathrm{~mm}$ 의 디스크

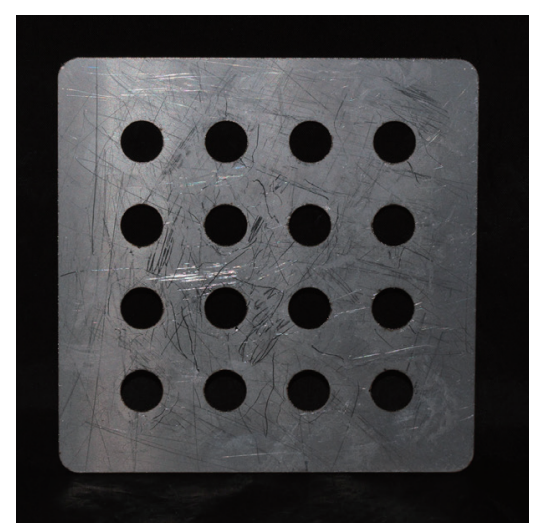

Fig. 1. Metal mold for fabricating provisional prosthetic materials by conventional method.

Table 1. Materials used in this study

\begin{tabular}{cccccc}
\hline Group & $\mathrm{N}$ & Product & Methods & Composition & Manufacturer \\
\hline CON & 20 & Tokuso CureFast & Conventional & Polymethyl methacrylates & $\begin{array}{c}\text { Tokuyama Dental, } \\
\text { Tokyo, Japan }\end{array}$ \\
MIL & 20 & PMMA DISK & Subtractive manufacturing & Polymethyl methacrylates & $\begin{array}{c}\text { Yamahachi Dental, } \\
\text { Gamagori, Japan } \\
\text { DLP }\end{array}$ \\
& 20 & 3D polymer & Additive manufacturing & Bis-acrylic & $\begin{array}{c}\text { Myeong Moon dental, } \\
\text { Daegu, Korea }\end{array}$ \\
\hline
\end{tabular}


를 디자인하여 PMMA 블록을 밀링기(ARUM 5X-200, $\mathrm{DOOWON} \mathrm{ID})$ 로 절삭하였다. DLP군의 시편 제작에 는 DLP 타입 3D 프린터(DIO PROBO, DIO)를 사용하 였다. CAD software로 직경 $10 \mathrm{~mm}$, 두께 $2 \mathrm{~mm}$ 의 디스 크를 디자인한 후 광경화성 수지가 담겨 있는 수조에 자 외선을 이용하여 중합 및 경화하였다. 제작이 완료된 시 편들은 광중합기에서 최종 경화시켰다.

제작된 각 종류의 20 개 시편을 무작위로 2 개의 그룹으 로 나눈 후 증류수에 침전시켜 37도 항온수조에 보관하 였다. 24시간 뒤 기준 값 설정을 위해 CIE Lab값을 측정 하였다. 그 후 각각 커피(KANU mild americano, Dongsuh Foods Co., Seoul, Korea)와 와인(G7 Cabernet Sauvignon, G7, Maule, Chile)에 침전시켜 37도 항온수조에 보관하였다. 모든 용액은 3 일에 1 번 교체하였고, 측정 시 모든 시편은 증류수에 세척된 후 초음파 세척기에서 5 분 간 세척되어 깨끗한 페이퍼타월로 건조되었다. 색 변화에 대한 평가는 4주간 매주 시행되었으며 각 시편은 비색계 (ZE 2000, Nippon Denshoku, Tokyo, Japan)를 이용하 여 색을 4회 반복 측정하여 시편 별 CIE Lab값을 기록하 였다(Fig. 2). CIE (International Commission on Illumination) $\mathrm{LAB}$ 색 공간을 사용했으며 아래의 공식을 이용 하여 색 변화량 $\left(\Delta \mathrm{E}^{*}\right)$ 을 계산하였다. ${ }^{12}$

$$
\Delta \mathrm{E}^{*}=\left[\left(\Delta \mathrm{L}^{*}\right)^{2}+\left(\Delta \mathrm{a}^{*}\right)^{2}+\left(\Delta \mathrm{b}^{*}\right)\right]^{1 / 2}
$$

통계 분석은 IBM SPSS 19 (SPSS Inc, Chicago, USA) 를 이용하였다. 제작방법에 따른 임시 보철 재료에 따른 $\Delta \mathrm{E}^{*}$ 값의 비교분석을 위해 One-way ANOVA와 사후 검 정으로 Tukey test를 실시하였다. 침전 기간에 따른 $\Delta \mathrm{E}^{*}$

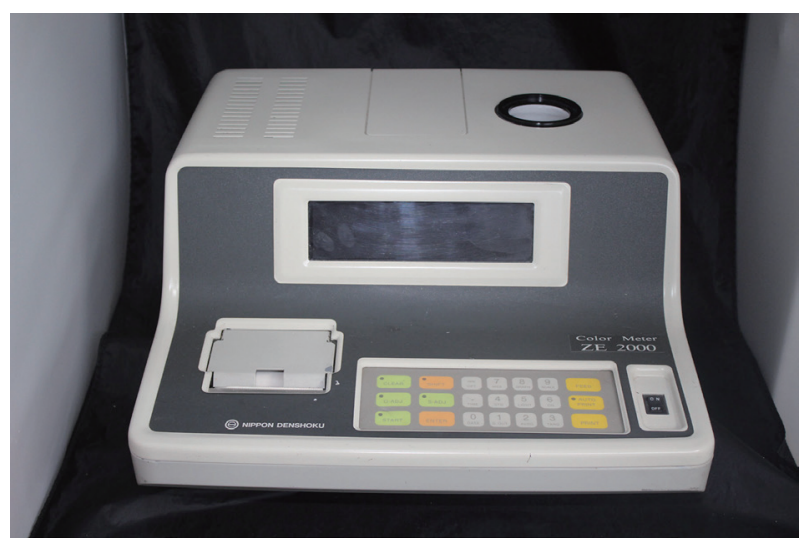

Fig. 2. Colorimeter (ZE 2000, Nippon Denshoku, Tokyo, Japan) used in this study.
값의 변화 관찰을 위해 단순회귀분석을 시행하였고 유의 수준은 $P<0.05$ 로 하였다.

\section{결과}

커피 용액에 침전시켰을 때 1 주 후, $\mathrm{CON}$ 군의 색 변화 량 $\left(\Delta \mathrm{E}^{*}\right)$ 은 2.02, MIL군은 1.17 그리고 DLP군은 5.97이 었다. CON군과 MIL군은 유의성 있는 차이를 보이지 않 았고 $(P>0.05), \mathrm{DLP}$ 군보다 유의성 있게 높은 색 안정 성을 보였다 $(P<0.05)$. 2주 후, $\mathrm{CON}$ 군의 색 변화량은 $1.44, \mathrm{MIL}$ 군은 1.56 그리고 $\mathrm{DLP}$ 군은 8.13이었다. $\mathrm{CON}$ 군과 MIL군은 유의성 있는 차이를 보이지 않았고 $(P>$ $0.05), \mathrm{DLP}$ 군보다 유의성 있게 높은 색 안정성을 보였다 $(P<0.05) .3$ 주 후, $\mathrm{CON}$ 군의 색 변화량은 2.54 , MIL군 이 1.61 그리고 DLP군은 9.20이었다. 통계학적으로 MIL 군이 유의하게 우수하였고 $(P<0.05)$, DLP군이 유의하 게 열악한 색 안정성을 보였다 $(P<0.05)$. 4주 후, $\mathrm{CON}$ 군의 색 변화량은 2.66, MIL군은 2.10 그리고 DLP군은 10.02 이었다. $\mathrm{CON}$ 군과 MIL군은 유의성 있는 차이를 보이지 않았고 $(P>0.05)$, DLP군보다 유의성 있게 높은 색 안정성을 보였다 $(P<0.05$, Fig. 3). 따라서 4주동안 평 균 색 변화량은 DLP군이 8.33로 유의성 있게 가장 큰 색 변화를 나타냈고, MIL군이 1.61로 가장 높은 색 안정성 을 보였으나 $\mathrm{CON}$ 군의 색 변화량과 유의성 있는 차이는 없었다 $(P>0.05$, Table 2).

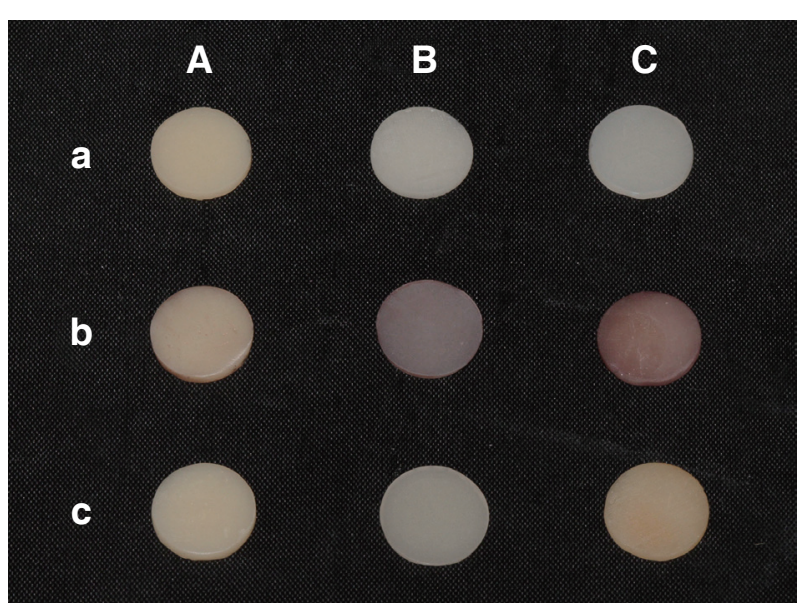

Fig. 3. (A), (B) and (C) are each CON group, MIL group and DLP group. Samples of the first horizontal line (a) are materials after 1 days in distilled water and samples of second (b) and third horizontal line (c) are each materials after 4 weeks in wine and coffee. 
Table 2. Mean $\Delta \mathrm{E}^{*}$ at different time intervals when immersed in coffee

\begin{tabular}{cccccc}
\hline & 1 & 2 & 3 & 4 & Average \\
\hline CON & $2.02(0.51)^{\mathrm{a}}$ & $1.44(0.33)^{\mathrm{a}}$ & $2.54(0.75)^{\mathrm{a}}$ & $2.66(0.66)^{\mathrm{a}}$ & $2.16(0.74)^{\mathrm{a}}$ \\
MIL & $1.17(0.48)^{\mathrm{a}}$ & $1.56(0.28)^{\mathrm{a}}$ & $1.61(0.33)^{\mathrm{b}}$ & $2.10(0.52)^{\mathrm{a}}$ & $1.61(0.52)^{\mathrm{a}}$ \\
DLP & $5.97(1.10)^{\mathrm{b}}$ & $8.13(1.00)^{\mathrm{b}}$ & $9.20(1.15)^{\mathrm{c}}$ & $10.02(1.25)^{\mathrm{b}}$ & $8.33(1.88)^{\mathrm{b}}$ \\
\hline
\end{tabular}

The same superscript small letters indicate no significant differences $(P>0.05)$.

CON: Conventional method, PMMA; MIL: Subtractive manufacturing, PMMA block; DLP: Additive manufacturing, bis-acrylate resin.

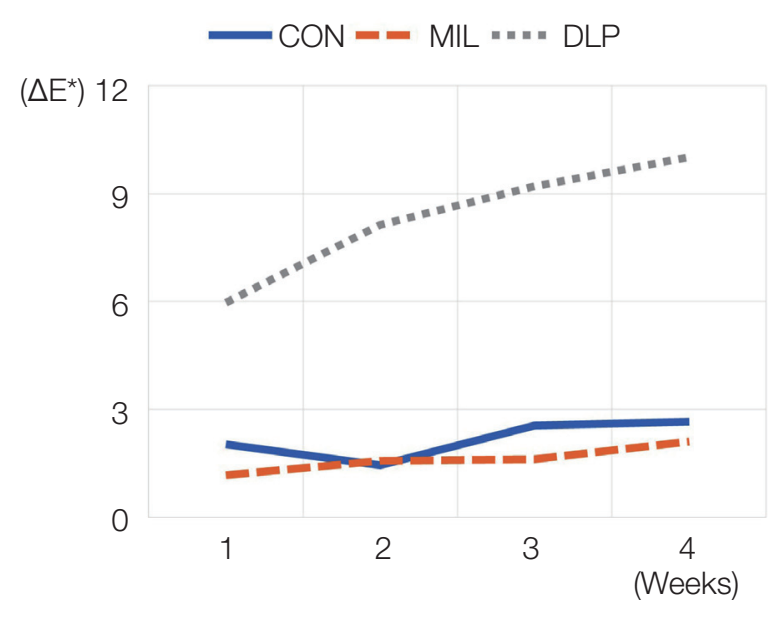

Fig. 4. Mean color change values $\left(\Delta E^{*}\right)$ of materials in coffee increased as the immersion period increased $(P<$ 0.05).

그리고 커피 용액에서 침전 기간이 증가함에 따른 각 재료의 색 안정성의 변화를 살펴보면 MIL군은 $\mathrm{CON}$ 군 과 유사하게 1주에서 4주까지 1.17, 1.44, 2.54, 2.66의 값 을 보였으나, DLP군은 1주부터 임상적으로 허용 가능한 색 변화의 역치 수준인 3.3보다 높은 5.97의 색 변화량을 보이며 2주에 8.13, 3주에 9.20, 4주에 10.02로 증가하였 다. MIL군, CON군 그리고 DLP군 모두에서 시간이 지
남에 따라 색 변화량이 증가하였다 $(P<0.05$, Fig. 4).

와인 용액에 침전시켰을 때 1 주 후, $\mathrm{CON}$ 군의 색 변화 량 $\left(\Delta \mathrm{E}^{*}\right)$ 은 2.44 , MIL군은 1.45 그리고 $\mathrm{DLP}$ 군은 4.43 이었다. 통계학적으로 MIL군이 유의하게 우수하였고 $(P$ $<0.05)$, DLP군은 유의하게 열악한 색 안정성을 보였다 $(P<0.05)$. 2주 후, $\mathrm{CON}$ 군의 색 변화량은 2.69, MIL군 은 2.13 그리고 DLP군은 5.94이었다. CON군과 MIL군 은 유의성 있는 차이를 보이지 않았고 $(P>0.05)$, DLP군 보다 유의성 있게 높은 색 안정성을 보였다 $(P<0.05) .3$ 주 후, $\mathrm{CON}$ 군의 색 변화량은 3.32, MIL군은 3.20 그리 고 DLP군은 7.53이었다. CON군과 MIL군은 유의성 있 는 차이를 보이지 않았고 $(P>0.05), \mathrm{DLP}$ 군보다 유의성 있게 높은 색 안정성을 보였다 $(P<0.05)$. 4주 후, $\mathrm{CON}$ 군의 색 변화량은 3.45 , MIL군은 3.24 그리고 DLP군은 7.56이었다. CON군과 MIL군은 유의성 있는 차이를 보 이지 않았고 $(P>0.05)$, DLP군보다 유의성 있게 높은 색 안정성을 보였다 $(P<0.05$, Fig. 3). 따라서 4주동안 평균 색 변화량은 DLP군이 6.37로 유의성 있게 가장 큰 색 변 화를 나타냈고 $(P<0.05), \mathrm{MIL}$ 군은 2.51로 가장 낮은 색 변화를 보였으나 CON군의 색 변화량과 유의성 있는 차 이는 없었다 $(P>0.05$, Table 3$)$.

와인 용액에서 침전 기간에 따른 각 재료의 색 안정성 의 변화를 보면 MIL군은 1주에서 4주까지 $1.45,2.13$, $3.20,3.24$ 의 값을 보였고, $\mathrm{CON}$ 군은 $2.44,2.69,3.32$,

Table 3. Mean $\Delta \mathrm{E}^{*}$ at different time intervals when immersed in wine

\begin{tabular}{cccccc}
\hline & 1 & 2 & 3 & 4 & Average \\
\hline CON & $2.44(0.41)^{\mathrm{a}}$ & $2.69(0.61)^{\mathrm{a}}$ & $3.32(0.44)^{\mathrm{a}}$ & $3.45(0.56)^{\mathrm{a}}$ & $2.98(0.65)^{\mathrm{a}}$ \\
MIL & $1.45(0.32)^{\mathrm{b}}$ & $2.13(0.67)^{\mathrm{a}}$ & $3.20(0.44)^{\mathrm{a}}$ & $3.24(0.58)^{\mathrm{a}}$ & $2.51(0.92)^{\mathrm{a}}$ \\
DLP & $4.43(1.28)^{\mathrm{c}}$ & $5.94(0.69)^{\mathrm{b}}$ & $7.53(0.19)^{\mathrm{b}}$ & $7.56(1.10)^{\mathrm{b}}$ & $6.37(1.58)^{\mathrm{b}}$ \\
\hline
\end{tabular}

The same superscript small letters indicate no significant differences $(P>0.05)$.

CON: Conventional method, PMMA; MIL: Subtractive manufacturing, PMMA block; DLP: Additive manufacturing, bis-acrylate resin. 


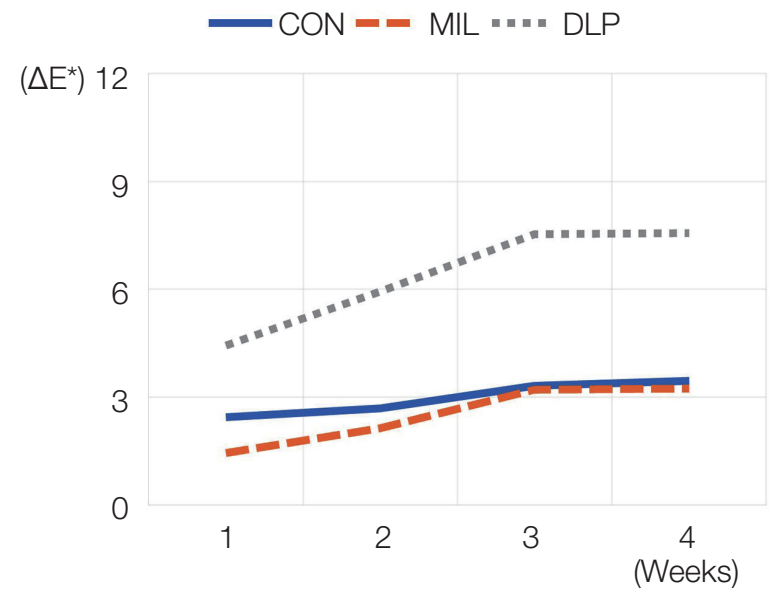

Fig. 5. Mean color change values $\left(\Delta E^{*}\right)$ of materials in wine increased as the immersion period increased $(P<$ 0.05).

3.45 의 값을 나타냈다. DLP군은 1 주부터 임상적으로 허 용 가능한 색 변화의 역치 수준인 3.3보다 높은 4.43의 색 변화량을 보이며 2주에 5.94, 3주에 7.53 4주에 7.56으로 증가하였다. CON군, MIL군 그리고 DLP군에서 모두 시간이 지남에 따라 색 변화량이 증가하였다 $(P<0.05$, Fig. 5).

\section{고찰}

치과분야에서 CAD-CAM 시스템의 활용이 점차 늘어 나고, 임플란트 시술의 증가로 임시 보철물의 사용기간 이 증가되면서, ${ }^{13}$ 임시 보철물의 색 안정성이 더욱 중요 해지는 추세이다. 전치부와 같이 심미적으로 중요한 부 위에서 임시 보철물의 색은 환자의 만족도와도 연결되므 로 심미부위에서 임시 수복의 성공여부는 색 안정성과 변 색저항성이라 볼 수 있다. 그러나 선행 연구의 대부분이 전통적인 방식과 PMMA 블록을 절삭가공한 방식을 비 교하는 연구에 국한되었으며, 적층가공 방식을 이용해 제작된 임시 보철 재료 간의 색 안정성과 관련된 연구는 부족하다. 이에 본 연구에서는 전통적인 방법과 CAD$\mathrm{CAM}$ 방식 중 절삭가공과 적층가공으로 제작한 임시 보 철 재료의 색 안정성을 비교 평가하고자 하였다.

색의 인지는 피로도, 노화, 감정, 빛의 상태, 그리고 조 건등색과 같은 조절되지 않는 많은 요인들에 영향을 받 지만, ${ }^{14}$ 비색계(colorimeter)나 분광측정기(spectropho- tometer)와 같은 기계를 이용하여 색을 측정하면 주관적 인 오차를 제거할 수 있다. 따라서 본 연구에서는 비색계 를 이용하여 색을 측정하였으며, 선행 연구에 따라, ${ }^{15} 3.3$ 을 임상적으로 허용 가능한 역치 값으로 정하였다. ${ }^{16}$

본 실험결과 MIL군은 $\mathrm{CON}$ 군보다 색 변화가 적었으 나 커피에 침전한 시편을 3 주차에 측정한 값을 제외하 고는 통계적으로 유의한 차이가 없었다 $(P>0.05)$. 또한 MIL군은 4주까지 임상적으로 허용가능한 역치보다 낮 은 색 변화량을 보였다. 이에 절삭가공을 이용하여 제작 한 임시 보철물과 전통적인 방법으로 제작한 임시 보철 물은 우수한 색 안정성을 갖고 있다고 볼 수 있다. 절삭 가공은 최적의 조건하에서 중합되어 잔존 모노머의 양이 매우 적고 압축으로 기포를 최소화한 블록을 절삭하므 로 색 안정성이 뛰어난 것으로 예상할 수 있다. ${ }^{17}$

DLP군의 색 변화량은 1 주부터 임상적으로 허용 가능 하지 않은 역치를 넘으며 CON군과 MIL군에 비해 낮은 색 안정성을 보였다 $(P<0.05)$. 이에 적층가공을 이용해 임시 보철물 제작 시 절삭가공에 비해 낮은 색 안정성을 가질 것이라 예상할 수 있으며 이는 제작 방식 및 제작방 식에 따른 사용된 재료의 차이로 사료된다. 소재를 적층 하는 적층가공의 특성 상 미세구조 표면에 층이 존재할 수밖에 없고 이는 낮은 색 안정성에 영향을 줄 수 있다. ${ }^{18}$ ${ }^{20}$ 치과재료의 색 안정성에 영향을 미치는 요인은 앞서 언 급되었던 중합정도(모노머-폴리머 전환율), 잔존 모노머 의 양 ${ }^{21}$ 외에도 아민과 중합억제제, ${ }^{22}$ 수분 흡수성, 광개시 제의 종류 그리고 외부 물질에 의한 색소의 흡착과 흡수 가 있다. ${ }^{23}$

적층가공에 사용할 수 있는 임시 보철 재료는 여 러 종류가 시판되고 있으며, 최근에 소개되는 대부분 은 UV 광경화성 수지 형태로 출시된다. 일반적으로 bisphenol-A glycerolatedimethacrylate (Bis-GMA), triethylene glycoldimethacrylate (TEGDMA) 등의 단 량체가 주요 성분이며 광개시제로는 다양한 유형의 bis (2,4,6-trimethylbenzoyl) phenyl phosphine oxide (BAPO), diphenyl (2,4,6-trimethylbenzoyl) phosphine oxide (TPO), camphorquinone (CQ) 등이 포함된다. ${ }^{24}$ 이 중 TPO나 $\mathrm{BAPO}$ 는 중합과정의 열로 발생한 유색의 과산화물로 인해 변색에 영향을 준다. TPO보다 BAPO 가 큰 색 변화를 일으키며 ${ }^{25}$ 함유량이 많을수록 색 변화 도 커진다. ${ }^{26}$ 적층가공에 이용되는 $3 \mathrm{D}$ 프린터 재료의 중 합속도는 느리므로 광개시제의 영향을 많이 받으며 낮은 색 안정성에 영향을 줄 수 있다. ${ }^{27}$ 전통적인 방법과 절삭 
가공에 주로 사용되는 PMMA 기반의 임시 보철 재료는 균질한(homogeneous) 조성을 갖고 있으나 적층가공에 사용되는 임시 보철 재료는 여러 다른 종류로 이루어져 있으므로(heterogenous) 착색용액이 흡수되거나 흡착되 기가 용이하다. 착색용액이 물질의 작은 입자들로 침투 할 수 있고 색 안정이 떨어질 수 있다. ${ }^{28}$ 또한 높은 수분흡 수성도 낮은 색 안정성에 기여할 것이다. ${ }^{29}$

본 실험에서 커피용액과 와인 용액의 모든 군에서 침전 기간이 커질수록 색 변화가 커지는 것을 관찰할 수 있었 다 $(P<0.05)$. 커피용액에서 MIL군은 $\mathrm{CON}$ 군과 유사하 게 비교적 낮은 기울기를 보이며 색 변화량이 증가하였 으나 임상적으로 허용가능한 범위 내에 있었다. 그러나 DLP군은 1주부터 임상적으로 허용 가능한 역치보다 높 은 색 변화량을 보이며 시간이 지날수록 색 안정성이 급 격히 떨어졌다. 와인용액에서 MIL군과 CON군은 커피 용액에서와 마찬가지로 비교적 완만한 기울기로 색 변화 량이 증가하였으나 DLP군은 1주부터 임상적으로 허용 가능한 색 변화의 역치를 넘으며 3주까지 가파르게 증가 하였다.

적층가공에 사용되는 광경화 수지는 사용 전 충분히 혼합하지 않을 시 색상 편차가 발생할 수 있다고 제품에 명시되어 있으므로 제작과정에서 생길 수 있는 변수도 결 과에 영향을 미칠 수 있다. 또한 각 제조사에서 제시하는 특정 3D 프린터로 출력을 권하고 있어 3D 프린터 장비 의 광원의 종류나 세기의 차이에 의한 영향도 있을 것이 라 예상된다. 각 제조업체의 광경화 수지를 구성하는 주 성분과 광개시제의 종류 등은 자세히 공개되지 않으며 각 제품마다 차이가 있으므로 다른 성분의 적층가공 재 료의 색 안정성에 대한 추가적인 연구가 필요할 것으로 사료된다.

\section{결론}

본 연구의 한계 내에서 절삭가공으로 제작된 임시 보 철 재료는 전통적인 방법을 이용해 제작한 경우와 유사 한 색 안정성을 보였고 $(P>0.05)$, 적층가공으로 제작된 임시 보철 재료에 비해 뛰어난 색 안정성을 보였다 $(P<$ 0.05). 시간이 경과함에 따라 적층 및 절삭가공을 이용하 여 제작한 임시보철 재료 모두에서 색 변화가 증가하였 으나 $(P<0.05)$, 적층가공으로 제작된 임시 보철 재료는 지속적이고 급격하게 색 안정성이 떨어졌고, 절삭가공으 로 제작된 임시 보철 재료는 전통적인 방법을 통해 제작
된 임시 보철 재료와 비슷하게 안정된 색 안정성을 보였 다. 따라서 전치부와 같이 심미가 중요한 부위에서는 절 삭가공을 통한 임시 보철물 제작을 추천하며, 적층가공 을 이용해 임시 보철물 제작 시에는 색 안정성에 대한 고 려가 필요하다.

\section{ORCID}

Young-Ji Lee https://orcid.org/0000-0003-4436-8109

Sang-Chun Oh https://orcid.org/0000-0001-5496-126X

\section{References}

1. Nejatidanesh F, Lotfi HR, Savabi O. Marginal accuracy of interim restorations fabricated from four interim autopolymerizing resins. J Prosthet Dent 2006;95:364-7.

2. Bello A, Jarvis RH. A review of esthetic alternatives for the restoration of anterior teeth. J Prosthet Dent 1997;78:437-40.

3. Sham AS, Chu FC, Chai J, Chow TW. Color stability of provisional prosthodontic materials. J Prosthet Dent 2004;91:447-52.

4. Doray PG, Li D, Powers JM. Color stability of provisional restorative materials after accelerated aging. J Prosthodont 2001;10:212-6.

5. Tallarico M. Computerization and digital workflow in medicine: Focus on digital dentistry. Materials 2020;13:2172.

6. Rayyan MM, Aboushelib M, Sayed NM, Ibrahim A, Jimbo R. Comparison of interim restorations fabricated by CAD/CAM with those fabricated manually. J Prosthet Dent 2015;114:414-9.

7. Almohareb T, Alkatheeri MS, Vohra F, Alrahlah A. Influence of experimental staining on the color stability of indirect computer-aided design/computeraided manufacturing dental provisional materials. Eur J Dent 2018;12:269-74.

8. Elagra MI, Rayyan MR, Alhomaidhi MM, Alanaziy AA, Alnefaie MO. Color stability and marginal integrity of interim crowns: An in vitro study. Eur J Dent 2017;11:330-4.

9. Shin JW, Kim JE, Choi YJ, Shin SH, Nam NE, Shim JS, Lee KW. Evaluation of the color stability 
of 3D-printed crown and bridge materials against various sources of discoloration: An in vitro study. Materials 2020;13:5359.

10. Gruber S, Kamnoedboon P, Özcan M, Srinivasan M. CAD/CAM complete denture resins: An in vitro evaluation of color stability. J Prosthodont 2020 Aug 31. doi: 10.1111/jopr.13246.

11. Revilla-León M, Umorin M, Özcan M, Piedra-Cascón W. Color dimensions of additive manufactured interim restorative dental material. J Prosthet Dent 2020;123:754-60.

12. Rosentritt M, Esch J, Behr M, Leibrock A, Handel G. In vivo color stability of resin composite veneers and acrylic resin teeth in removable partial dentures. Quintessence Int 1998;29:517-22.

13. Park JS, Park MG. Effect of aging treatment on the flexural properties of polymer provisional restoration materials. Korean J Dent Mater 2013;40:21521.

14. Wyszecki G, Stiles WS. Color Science: Concepts and Methods, Quantitative Data and Formulae. 2nd ed. New York; John Wiley and Sons; 2000. p. 83116.

15. Schulze KA, Marshall SJ, Gansky SA, Marshall GW. Color stability and hardness in dental composites after accelerated aging. Dent Mater 2003;19:612-9.

16. Ruyter IE, Nilner K, Möller B. Color stability of dental composite resin materials for crown and bridge veneers. Dent Mater 1987;3:246-51.

17. Ruyter IE, Svendsen SA. Remaining methacrylate groups in composite restorative materials. Acta Odontol Scand 1978;36:75-82.

18. Garcia CR, Rumpf RC, Tsang HH, Barton JH. Effects of extreme surface roughness on 3D printed horn antenna. Electron Lett 2013;49:734-6.

19. Ngo TD, Kashani A, Imbalzano G, Nguyen KTQ, Hui D. Additive manufacturing (3D printing): A review of materials, methods, applications and challenges. Compos B Eng 2018;143:172-96.

20. Vaezi M, Seitz H, Yang S. A review on 3D microadditive manufacturing technologies. Int $\mathrm{J} \mathrm{Adv}$ Manuf Technol 2013;67:1721-54.

21. Ferracane JL, Moser JB, Greener EH. Ultraviolet light-induced yellowing of dental restorative resins. J Prosthet Dent 1985;54:483-7.
22. Abu-Bakr N, Han L, Okamoto A, Iwaku M. Color stability of compomer after immersion in various media. J Esthet Dent 2000;12:258-63.

23. Asmussen E. Factors affecting the color stability of restorative resins. Acta Odontol Scand 1983;41:118.

24. Park SJ, Lee HA, Lee SH, Seok S, Lim BS, Kwon JS, Kim KM. Comparison of physical properties of the various 3D printing temporary crown and bridge resin. Korean J Dent Mater 2019;46:139-52.

25. Bertolo MV, Moraes RC, Pfeifer C, Salgado VE, Correr AR, Schneider LF. Influence of Photoinitiator System on Physical-Chemical Properties of Experimental Self-Adhesive Composites. Braz Dent J 2017;28:35-9.

26. Hadis MA, Shortall AC, Palin WM. Competitive light absorbers in photoactive dental resin-based materials. Dent Mater 2012;28:831-41.

27. Kim JE, Choi WH, Lee D, Shin Y, Park SH, Roh BD, Kim D. Color and Translucency Stability of ThreeDimensional Printable Dental Materials for Crown and Bridge Restorations. Materials 2021;14:650.

28. Mazaro JVQ, Minani LM, Zavanelli AC, Mello CCD, Lemos CAA. Evaluation of color stability of different temporary restorative materials. Rev Odontol UNESP 2015;44:262-7.

29. Berli C, Thieringer FM, Sharma N, Müller JA, Dedem P, Fischer J, Rohr N. Comparing the mechanical properties of pressed, milled, and 3Dprinted resins for occlusal devices. J Prosthet Dent 2020;124:780-6. 


\section{고정성 임시 보철물 재료의 색 안정성에 대한 절삭 및 적층가공법의 비교평가}

이영지 대학원생, 오상천* 교수

원광대학교 치과대학 치과보철학교실

목적: 본 연구의 목적은 CAD-CAM 방식 중 절삭가공과 적층가공으로 제작한 임시 보철 재료의 색 안정성을 비교 연구 하는 것이다.

연구 재료 및 방법: 절삭가공을 통해 제작한 PMMA계열, DLP타입 프린터와 광경화성 수지를 이용해 적층가공으로 제 작한 bis-acryl계열 그리고 전통적인 방법으로 제작한 PMMA계열의 시편을 각 20개씩 제작하였다. 시편을 커피용액과 와인용액에 침전시킨 후, 비색계를 이용하여 4주간 매주 색 측정을 시행하였다. 색 변화 $\left(\Delta \mathrm{E}^{*}\right)$ 값의 비교분석을 위해 Oneway ANOVA와 사후 검정으로 Tukey test를 실시하였다 $(\alpha=0.05)$.

결과: 절삭가공을 통해 제작된 PMMA계열의 시편은 적층가공을 통해 제작된 bis-acryl계열의 시편에 비해 뛰어난 색 안 정성을 보였고 $(P<0.05)$, 전통적인 방법을 통해 제작된 PMMA계열의 시편과 유사한 색 안정성을 보였다 $(P>0.05)$.

결론: 전치부와 같이 심미가 중요한 부위에서는 절삭가공을 통한 임시 보철물의 제작을 추천하며, 적층가공을 이용한 임 시 보철물 제작 시에는 색 안정성에 대한 고려가 필요하다.

(구강회복응용과학지 2021;37(2):73-80)

주요어: 색 안정성; $\mathrm{CAD}-\mathrm{CAM}$; 절삭가공; 적층가공

*교신저자: 오상천

(35233) 대전광역시 서구 둔산로 77 원광대학교 대전치과병원 치과보철과

Tel: 042-366-1102 | Fax: 042-366-1115 | E-mail: scoh@wku.ac.kr

접수일: 2021년 1월 20일 | 수정일: 2021년 2월 21일 | 채택일: 2021년 3월 12일 